\title{
Child Soldiers, Executive Functions, and Culpability
}

\author{
Tyler Fagan, William Hirstein and Katrina Sifferd \\ Department of Philosophy, Elmhurst College, Elmhurst, IL, USA \\ tyler.fagan@net.elmhurst.edu;williamh@elmhurst.edu; sifferdk@elmhurst.edu
}

\begin{abstract}
Child soldiers, who often appear to be both victims and perpetrators, present a vexing moral and legal challenge: how can we protect the rights of children while seeking justice for the victims of war crimes? There has been little stomach, either in domestic or international courts, for prosecuting child soldiers-but neither has this challenge been systematically addressed in international law. Establishing a uniform minimum age of criminal responsibility would be a major step in the right direction; we argue that such a standard ought to be guided by the best evidence from neuropsychology about the development, during childhood and adolescence, of executive functions that give rise to morally and legally responsible agents. In light of that evidence, which suggests that the brain's executive functions are still maturing into early adulthood, we recommend a graded structure of culpability for child soldiers.
\end{abstract}

\section{Keywords}

child soldiers - age of criminal responsibility - neuroscience - executive function moral development

\section{Introduction}

Estimates suggest that roughly 300,000 children are presently engaged in armed conflicts around the globe; ${ }^{1}$ and although nobody truly knows what

1 Guide to the Optional Protocol on the Involvement of Children in Armed Conflict, December 2003, Coalition to Stop the Use of Child Soldiers / UNICEF, <www.unicef.org/emerg/files/ option_protocol_conflict.pdf>, 30 June 2015. 
the accurate figure is, all reasonable people can agree it is too high. According to the UN Convention on the Rights of the Child (CRC) and customary law, a child is any person under the age of 18 . Child soldiers are often treated with stunning cruelty: recruited forcibly or abducted outright, made to witness the deaths of their family members, subject to long periods of abuse and harsh punishments. ${ }^{2}$ Then again, child soldiers have also participated in some of the worst atrocities in modern warfare, including murder, torture, mutilation, and rape. ${ }^{3}$ Such crimes cry out for justice, but what justice demands is far from clear in the case of child soldiers, who often appear to be both victims and perpetrators. ${ }^{4}$ Child soldiers thus present a vexing legal and ethical challenge.

The Geneva Conventions Additional Protocols of 1977 codified the notion that child soldiers merit privileged treatment compared to their adult counterparts. ${ }^{5}$ The Rome Statute of the International Criminal Court (ICC) makes it a war crime for both State and non-State actors to conscript or enlist anyone under 15 - a declaration that would seem to guarantee protected status for many child soldiers, since any soldier younger than 15 will be classified as a victim of war crimes, and hence unlikely to be considered a perpetrator. ${ }^{6}$ The CRC urges a special, protected status for children, and marks the recruitment or exploitation of juveniles as an especially grievous crime. ${ }^{7}$

In general, State courts have been reluctant to prosecute child soldiers. However, international law has not definitively ruled out the possibility of such prosecutions. ${ }^{8}$ Although the ICC has no jurisdiction over any person who was

2 Timothy Webster, 'Babes with Arms: International Law and Child Soldiers', 39 Geo. Wash. Int'l L. Review (2007) 227-254, p. 227.

3 Matthew Happold, 'Child Soldiers: Victims or Perpetrators?', 29 University of La Verne Law Review (2008) 56-87.

4 The Secretary-General, Report of the Secretary-General on the Establishment of a Special Court for Sierra Leone (U.N. Doc. S/200o/915), p. 7 .

5 Protocol Additional to the Geneva Conventions of 12 August 1949, and Relating to the Protection of Victims of International Armed Conflicts (8 June, 1977); Protocol Additional to the Geneva Conventions of 12 August 1949 and Relating to the Protection of Victims of Non-International Armed Conflicts (8 June 1977).

6 Matthew Happold, 'The Age of Criminal Responsibility in International Law', in Karin Arts and Vesselin Popovski (eds.), International Criminal Accountability and the Rights of Children (The Hague Academic Press, The Hague, 2006), pp. 69-84.

7 UN General Assembly, Convention on the Rights of the Child (United Nations Treaty Series 1577, 20 November 1989).

8 Maria Achton Thomas, 'Malice Supplies the Age?: Assessing the Culpability of Adolescent Soldiers', 44 California Western International Law Journal (2013) 1-39. 
under 18 at the time he or she committed a crime, this jurisdictional limit is no substitute for an explicit principle regarding the prosecution of child soldiers; indeed, this provision was enacted to endorse local, domestic control of the question of juvenile culpability. ${ }^{9}$ The Special Court for Sierra Leone, established in 2002 with the help of the United Nations, was prepared to include children among its prosecutorial targets. ${ }^{10}$ There have been high-profile examples of child soldiers being prosecuted under domestic law: in 2000, the Congolese government executed a 14 year-old soldier, and in 2001, Human Rights Watch intervened to stop the Democratic Republic of Congo from carrying out death sentences imposed on four child soldiers. ${ }^{11}$ Since the attacks of 9/11, the United States has held at least fifteen juveniles in custody at Guantanamo Bay for prosecution by military commissions. ${ }^{12}$ The most wellknown such detainee is Omar Khadr, a Canadian citizen who was captured in Afghanistan in 2002 at age $15 .{ }^{13}$

The CRC includes the imperative that States establish a minimum age for criminal responsibility, but leaves it to individual States to determine what this age should be, and offers little guidance about what kinds of considerations should be in play in making such a determination. Generally, the minimum age for criminal responsibility falls between 13 and 15 years. ${ }^{14}$ This means that under the domestic law of many States, child soldiers may be held criminally responsible for violent acts related to their soldiering. Further, if the acts of a child soldier constitute a war crime, the child is subject to universal jurisdiction ${ }^{15}$

David M. Rosen, 'Who Is a Child?: The Legal Conundrum of Child Soldiers', 25 Conn J. Int. Law (2009) 81-118; Happold, supra note 3.

10 The Secretary-General, supra note 4.

11 Happold, supra note 6, p. 1.

12 Guantanamo's Children: The Wikileaked Testimonies, last revised 22 March 2013, Center for the Study of Human Rights in the Americas, University of California, Davis, <http:// humanrights.ucdavis.edu/reports/guantanamos-children-the-wikileaked-testimonies/ guantanamos-children-the-wikileaked-testimonies>, 30 June 2015 .

13 Happold, supra note 3.

14 Happold, supra note 6, p. 10.

15 War crimes are widely believed to fall under the principle of universal jurisdiction, which is described by Mary Robinson, the United Nations High Commissioner for Human Rights, as 'based on the notion that certain crimes are so harmful to international interests that states are entitled — and even obliged - to bring proceedings against the perpetrator, regardless of the location of the crime or the nationality of the perpetrator or victim'. See Stephen Macedo (ed.), The Princeton Principles on Universal Jurisdiction (Princeton, NJ, 2001), <http:// lapa.princeton.edu/hosteddocs/unive_jur.pdf>, 10 October 2015 . 
and may be prosecuted and punished by any State who gains possession of him or her. ${ }^{16}$ And while many child soldiers could plausibly be excused from prosecution via the defences of command responsibility, duress, or intoxication, ${ }^{17}$ there will be — and have been — cases where a child soldier's only plausible exculpatory defence would be on grounds of mental immaturity.

We agree with other scholars that have called for a universal minimum age of criminal responsibility for international crimes, which would allow for more consistent handling of child soldiers' responsibility across nation-states..$^{18} \mathrm{~A}$ universal understanding of the culpability of child soldiers is desirable for use by any State considering the criminal prosecution of a child soldier under domestic law. The value of such a cross-cultural uniform standard, and the difficulty of constructing one, is well expressed in the Commentary to Rule 4 of the UN Standard Minimum Rules for the Administration of Juvenile Justice—also known as the 'Beijing Rules':

The minimum age of criminal responsibility differs widely owing to history and culture. The modern approach would be to consider whether a child can live up to the moral and psychological components of criminal responsibility; that is, whether a child, by virtue of her or his individual discernment and understanding, can be held responsible for essentially antisocial behaviour. If the age of criminal responsibility is fixed too low or if there is no lower age limit at all, the notion of responsibility would become meaningless. In general, there is a close relationship between the notion of responsibility for delinquent or criminal behaviour and other social rights and responsibilities (such as marital status, civil majority, etc.). Efforts should therefore be made to agree on a reasonable lowest age limit that is applicable internationally. ${ }^{19}$

We propose a more sophisticated approach to determining the culpability of child soldiers than the universal use of binary minimum age of responsibility.

16 Happold, supra note 6, p. 10.

17 Angela Veale, 'The Criminal Responsibility of Minors? Contributions from Psychology', in Arts and Popovski supra note 6, pp. 97-108; Erin Lafayette, 'The Prosecution of Child Soldiers: Balancing Accountability with Justice', 63 Syracuse Law Review (2013) 297-325; Thomas, supra note 8.

18 In this we agree with, e.g., Happold, supra note 3; Happold, supra note 6; Lafayette, supra note 17 .

19 Office of the United Nations High Commissioner for Human Rights, United Nations Standard Minimum Rules for the Administration of Juvenile Justice (The Beijing Rules) (A/RES/40/33), 29 November 1985, <http://www.ohchr.org/EN/ProfessionalInterest/Pages/ BeijingRules.aspx $>$, 30 June 2015 
Our hypothesis, to be defended here, is that a minimum age of criminal responsibility should be guided by emerging evidence from neuropsychology about the development, during childhood and adolescence, of the executive functions necessary for criminal responsibility, and the unique environmental pressures that affect child soldiers' brain development. In light of that evidence, we will recommend not just a universal minimum age, but also a graded structure of culpability for child soldiers. We feel such a graded structure can be sensitive to local cultural notions of maturity, and at the same time provide a scientifically informed universal guide to States attempting to prosecute child soldiers. The structure we propose is this: Below the age of 15 , child soldiers should not be held responsible for crimes related to their soldiering, on the grounds of an irrebuttable presumption of incapacity to form the requisite mens rea for such crimes. That is, they do not have the mental capacity to plan and execute crimes, with full knowledge of the consequences of their acts. From the ages of 15 through 17 , child soldiers should be afforded that same presumption-only with the possibility of rebuttal. And starting at 18 , an offender should be under a rebuttable presumption of culpability.

Drawing stark lines of this sort inevitably involves some degree of arbitrariness, and choosing whether to prosecute a child soldier will never be anything other than a terrible decision; but our proposal balances the drive for individualised justice with the need for workable uniform standards. The presumption of incapacity for child soldiers between the ages of $15^{-17}$ is supported by the best brain science, but recognises the importance of local cultural or legal notions of maturity, and allows States the opportunity to use them to rebutable the presumption of incapacity. Similarly, the rebuttalable presumption of capacity for soldiers over 18 recognises the tendency of states to consider 18 the age of maturity, but allows for the possibility that States will take more seriously scientific evidence that brain development continues into a person's twenties. We thus feel our schema of graded culpability could encourage uniformity in the treatment of child soldiers, while at the same time allowing States some opportunity for consideration of local concerns.

\section{Executive Functions and Responsibility}

\section{1}

\section{What Are Executive Functions?}

There is a consensus emerging from neuroscience that the brain accomplishes higher level decisions using frontal processes known as executive functions, which 
manipulate mental representations to produce intelligent behaviour. ${ }^{20}$ In general, executive functions activate when we must go out of our routine mode of acting and plan more complicated actions, but they may also activate when the stakes are very high, or when special care is needed in performing an action. They interact with mental representations (perceptual and mnemonic) and emotions to plan and execute behaviours. While the work of making a canonical list of executive processes is ongoing, the following core set can be derived from the literature: ${ }^{21}$

- Attention (top-down). Top-down attention, which we normally view as under voluntary control, is crucial for most of the other executive functions to accomplish their tasks. Attention includes the ability to monitor perceptions and memories, which allows for the correction of mistaken perceptions and 'false memories.'22

- Task monitoring. We also need to attend to ongoing tasks, to make sure they are going the way we intended.

- Task-switching. Many tasks require that we switch our attention back and forth between subtasks, while not losing our place in the unfinished tasks. Executive processes keep us on track while these subtasks are performed. ${ }^{23}$

- Planning and error correction. Plans can be devised and errors corrected when they are noticed. ${ }^{24}$

20 Richard A. Andersen, Lawrence H. Snyder, David C. Bradley, and Jing Xing, 'Multimodal Representation of Space in the Posterior Parietal Cortex and Its Use in Planning Movements', 20 Annual Review of Neuroscience (1997) 303-330.

21 Alan Baddeley, 'Fractionating the Central Executive', in D.T. Stuss and R.T. Knight (eds.), Principles of Frontal Lobe Function (Oxford University Press, Oxford, 2002), pp. 246-26o; Marie T. Banich, 'Executive Function: The Search for an Integrated Account', 18 Current Directions in Psychological Science (2009) 89-94. See also Fabienne Collette, Martial Van Der Linden, Steven Laureys, Guy Delfiore, Christian Degueldre, Andre Luxen and Eric Salmon, 'Exploring the Unity and Diversity of the Neural Substrates of Executive Functioning', 25 Human Brain Mapping (2005) 409-423; Michael W. Cole and Walter Schneider, 'The Cognitive Control Network: Integrated Cortical Regions with Dissociable Functions', 37 Neuroimage (2007) 343-36o.

22 Helen Barbas, 'Complementary Roles of Prefrontal Cortical Regions in Cognition, Memory, and Emotion in Primates', 84 Advances in Neurology (2000) 87-110.

23 Paul W. Burgess, Emma Veitch, Angela de Lacy Costello, and Tim Shallice, 'The Cognitive and Neuroanatomical Correlates of Multitasking', 38 Neuropsychologia (2000) 848-863.

24 Cameron S. Carter, Todd S. Braver, Deanna M. Barch, Matthew M. Botvinick, Douglas Noll, and Jonathan D. Cohen, 'Anterior Cingulate Cortex, Error Detection, and the Online Monitoring of Performance', 280 Science (1998) 747-749. 
- Inhibition. Some thoughts and intentions need to be inhibited prior to causing behaviour.

- Regulation of emotions. When we express emotions, where we express them, and how we express them is done according to complex social and interpersonal rules, all of which requires management by executive processes.

While they are accomplished by large brain networks, typically spanning several cortical areas and supported by additional subcortical areas, executive functions are accomplished primarily by the brain's prefrontal cortex. ${ }^{25}$

\subsection{Theoretical Underpinnings: Agency, Responsibility, and Punishment}

Executive functions, in our view, form the basis of moral and legal agency. ${ }^{26}$ This claim will require some defense, but it first requires the appropriate philosophical context - specifically, how we understand action and agency itself; how we conceive of the link between moral and legal responsibility; and how we justify practices of legal blame or punishment. This article is obviously not the place to advance fully developed theories on these matters, but we can at least sketch the philosophical foundations of our position.

On the matters of action and agency, our sympathies lie with compatibilism and capacitarianism. Responsible agents, in the most general terms, need not be uncaused causers; human actions, just like all events in the physical world, have prior physical causal histories, but this does not erode agency and responsibility. Compatibilism, if not quite the 'official' position of the criminal law, is more than merely consistent with it: it is the consensus view. ${ }^{27}$ For example, prominent legal scholar Stephen Morse is a compatibilist who argues that even though human decisions and actions are causally determined, humans actions are 'free enough'-because they come from psychological states that are ours-for us to be responsible for them. ${ }^{28}$

25 Joaquin M. Fuster, 'Physiology of Executive Functions: The Perception-Action Cycle', in Stuss and Knight (eds.), supra note 21, pp. 96-108.

26 William Hirstein and Katrina Sifferd, 'The Legal Self: Executive Processes and Legal Theory', 20 Conscious Cognition (2011) 156-171.

27 Michael S. Moore, Placing Blame: A Theory of the Criminal Law (Oxford University Press, Oxford, 1997); Stephen J. Morse, 'Excusing and the New Excuse Defenses: A Legal and Conceptual Review', Crime and Justice (1998) 329-406.

28 Morse says, 'I am a compatibilist who believes that moral and criminal responsibility are compatible with determinism or universal causation'. Stephen J. Morse, 'The Mind of a Child: The Relationship between Brain Development, Cognitive Functioning, and Accountability under the Law: Brain Overclaim Syndrome and Criminal Responsibility: A Diagnostic Note', 3 Ohio St. J. Crim. L. (2006) 397-543, p. 398. 
The capacities necessary for responsibility can be conceived of in multiple ways. We think that what distinguishes a responsible agent from one who is not responsible is, in a word, control. Control is tied closely to rationality: an agent's control over her actions is grounded in her capacity to grasp and respond to reasons. Or, as Antony Duff puts it, control 'is a matter of rational capacities: thus I have control over my actions insofar as I have the capacities necessary to recognize reasons and guide my actions by them, insofar as I am capable of engaging in practical reasoning and of actualizing its results.'29 Similarly, Morse claims that only persons who have the capacity of rational thought may produce actions for which they are responsible. ${ }^{30}$ The capacitarian view of responsible action enjoys wide acceptance and considerable influence, and the philosophical literature surrounding it is large and welldeveloped. ${ }^{31}$ By situating our proposal within this theoretical framework, we are thus on familiar ground.

Since this article focuses on an area where legal and ethical concerns intersect, we shall also say a word about the relationship between moral and legal responsibility, and about our view of legal punishment in general. Clearly not everything for which a person is morally responsible is something for which she is legally responsible, and not everything that is an appropriate candidate for legal blame or punishment is immoral. However, with respect to the phenomenon of child soldiering and its attendant atrocities, we are in this article dealing with actions that are for the most part both morally wrong and unlawful. This means that although we acknowledge such a gap exists, we need not worry about describing the gap between legal and moral agency. We think the substance of our argument applies to both.

Because we are sceptical that any single approach to the justification of punishment can succeed, we favour "mixed" theories that make room for the different purposes that punishment aims to fulfil: these include both retributivist,

29 R. Antony Duff, 'Who Is Responsible, for What, to Whom?', 2 Ohio St. J. Crim. L. (2004) 441-461. One could find this picture of responsibility tempting - in terms of who is responsible, and for what—without being obliged to accept Duff's attempt to give it a relational, practice-based grounding.

30 Stephen J. Morse, 'Reason, Results, and Criminal Responsibility', U. Ill. L. Rev. (2004) 363444; Morse, supra note 27.

31 See, e.g., Hirstein and Sifferd, supra note 26; Duff, supra note 29; Morse, supra note 30; Paul Litton, 'Is Psychological Research on Self-Control Relevant to Criminal Law?', 11 Ohio State J. Crim L. (2014) 725-749; David O. Brink, 'Retributivism and Legal Moralism', 25 Ratio Juris (2012) 496-512.; Nicole A. Vincent, 'On the Relevance of Neuroscience to Criminal Responsibility', 4 Criminal Law and Philosophy (2010) 77-98. 
backward-looking goals (e.g., desert) and forward-looking ones (e.g., deterrence, rehabilitation). Norval Morris famously advocates this kind of account, ${ }^{32}$ which he called limiting retributivism; and some argue that it is the consensus model of criminal punishment in the United States and Europe..$^{33}$ Limiting retributivism claims retributive notions of just desert (which probably rest upon moral emotions) $)^{34}$ provide an appropriate range of justified penalty within which an offender might be sentenced. Backward-looking retributive considerations of proportionality are then to be balanced by forward-looking considerations of social order to create a punishment package that is proportional to crime and offender, but also aims to reduce recidivism and overall crime rates.

This sort of hybrid theory of punishment is not immune to challenges; yet, as with our view of responsible agency, it enjoys a wide base of support with a mature scholarly literature surrounding it. Nothing in our argument depends on adopting any particular version of such a "mixed" theory; our proposals are consistent with a broad range of possible views. But even in the context of a "mixed" theory of punishment, retributivist rationales are of central importance. To take another example, consider the "predominant retributivism" described by David Brink. ${ }^{35}$ This view is similar to limiting retributivism in that the predominant element of desert answers questions about whom to punish and why, but leaves open questions about how, and how much, to punish. In predominant retributivism, it is in these areas left open by considerations of desert — and only these areas — where forward-looking, consequentialist rationales properly gain a foothold. ${ }^{36}$

To see why this approach is a good fit for the specific topic of child soldiers, recall that the Beijing Rules cast the central question about child-soldier culpability in terms of 'whether a child can live up to the moral and psychological components of criminal responsibility; that is, whether a child, by virtue of her or his individual discernment and understanding, can be held responsible for essentially antisocial behaviour.'37 The idea implicit in this remark is that child

32 Norval Morris, 'The Future of Imprisonment: Toward a Punitive Philosophy', Michigan Law Review (1974) 1161-1180.

Richard S. Frase, 'Limiting Retributivism', in M. Tonry (ed.), The Future of Imprisonment (Oxford University Press, New York, 2004), pp. 83-120.

34 Michael S. Moore, Causation and Responsibility: An Essay in Law, Morals, and Metaphysics (Oxford University Press, Oxford, 2009).

35 Brink, supra note 31.

$36 \quad$ Ibid., pp. 502-3.

37 Office of the United Nations High Commissioner for Human Rights, supra note 19. 
soldiers should be punished only if their wrongdoing is culpable, which in turn depends on whether they satisfy a set of moral and psychological conditions necessary for legal and moral responsibility. As we will argue, child soldiers will very often fail to meet these conditions, although they draw closer to meeting them throughout adolescence and into early adulthood. Whether child soldiers are fit targets of criminal prosecution — and which ones, if any — is an instance of a 'Whom to punish and why?' question, and must therefore be answered in ways that are significantly constrained by desert. And since desert is commonly construed as a product of wrongdoing and culpability, ${ }^{38}$ the proper legal approach to child soldiers will depend in large part on whether child soldiers are responsible agents. Before taking up this latter question, though, we must give some account of how executive functions underwrite normative competence - and therefore moral and legal responsibility — in general.

\subsection{How Do Executive Functions Produce Responsible Persons?}

We propose that possessing a developed set of executive functions is a necessary, though not sufficient, condition for being a legally and morally responsible person. Executive processes allow persons to plan actions that involve other people; to include the beliefs and feelings of others in ongoing cognition; to withhold all manner of gratification until the appropriate time and place; and to temper the expression of emotions in a socially acceptable way. All of these capacities are important to a person functioning in a society as an effective and moral agent.

These processes alone may not suffice for full moral responsibility, however, as illustrated by examples like Susan Wolf's story of Jojo, the child raised and educated so that his moral perspective and behaviour wind up mirroring those of his father, a sadistic and evil dictator: such a child would employ executive processes for strictly strategic, self-centred reasons, just as successful psychopaths do in all contemporary societies. ${ }^{39}$ But surely, an objection goes, such a child, assuming he does not possess the genes that can produce a psychopath, would feel the tug of empathy when he hurt someone, since this is a basic,

38 Robert Nozick, Philosophical Explanations (Harvard University Press, Cambridge, MA, 1981); Brink, supra note 31 .

39 Susan Wolf, 'Sanity and the Metaphysics of Responsibility', in G. Watson (ed.), Free Will (Oxford University Press, Oxford, 2003), pp. 372-387; see Yu Gao and Adrian Raine, 'Successful and Unsuccessful Psychopaths: A Neurobiological Model', 28 Behavioral Sciences \& The Law (2010) 194-210; Andrea L Glenn, Adrian Raine and Ra Schug, 'The Neural Correlates of Moral Decision-Making in Psychopathy', 14 Molecular Psychiatry (2009) 5-6. 
inborn function of the human brain. Surely he would, but the function of executive processes is to determine what sort of weight should be attached to such feelings in planning and executing ongoing actions. We all have the ability to brush aside empathy when we know the situation demands it. A doctor must proceed with an injection on a child who is screaming. She must proceed with a spinal tap when her patient is obviously distressed. The unlucky person at every horse racing track who carries a high-calibre pistol for killing seriously injured horses must proceed despite his squeamish stomach. Without the surrounding context of an ethical society, which is brought to bear in the child partly by the actions of her parents, there is no reason to think that the fundamentally selfish nature that we are born with would ever be educated, corrected, and distilled into ethical actions. The development of executive processes in such a person would simply result in more clever and effective selfish actions.

Is it certain, however, that executive processes are required for moral behaviour? After all, some children seem to be born little angels. They share with their siblings and even begin to help them and care for them at a very early age, seemingly without being asked or ordered to. Contemporary life is complicated, however. Doing the right thing can require a lot of knowledge about the people involved - including the history of your relationship with them - the social conventions and experience with similar situations. And we cannot simply 'share' with everyone who asks, when we become adults, lest we find ourselves out of toys, and a house to put them in. We must carefully sort through the requests to share based on many factors, some of them quite subtle. In addition, children have yet to experience the real pressures that can tempt us all. They have not yet felt the temptations of the full range of human vices, temptations that we are all exposed to daily. These are among the ethical tests that adults must pass and, with the exception perhaps of a few saintly beings, the only way we can pass them is by developing robust executive functions powerful enough to correct and redirect our fundamentally selfish inclinations. And even saintly beings need to be able to weigh conflicting sources of information, the pull of their emotions, their simulations of events, and many other factors, in making more complex ethical decisions.

Common-sense approaches to morality generally treat actions, with their tight causal links to harms and benefits, as more ethically significant than thoughts. Hence the executive processes involved in the planning, inhibiting, and execution of actions tend to have more ethical importance than those involved in more purely cognitive activities, such as attention, monitoring of perceptions, memories, and emotions, which tend to be more neutral. Those latter processes still play important roles in producing ethical actions, however, 
as evidenced by the types of unethical behaviour caused by their malfunction. They play a role in making more difficult, or more pressing, ethical decisions.

Obviously the different executive functions do not work alone. They require the proper input, from perception, memory, and emotion, before they can work correctly. Among the many perceptual abilities, executive functions also utilise information from a special ability we have to understand each other by using our own bodies. Mirror neurons become active, e.g., when I pick up an almond off of a plate, or see you pick up an almond. Their existence, revealed in the early 1990s, made clear one trick the brain uses here: it has cells that have connections to both the motor system (that is how I pick up the almond), and to the visual system (that is how I understand your action of picking up the almond, as I watch you do so).

Complex decision-making also depends upon our ability to track the identities and behaviours of significant people. 'Significant' obviously cannot be defined purely in terms of spatial proximity, but that is one important factor, along with the sheer amount of space and computational power my brain devotes to representing and thinking about that person. Sighted people tend to use vision to track and gain knowledge about other people, but in the absence of that, it can be done with sound, or even touch in some cases. The executive system also needs to have access to a robust set of memory systems, since ethical agents need to be able to form detailed mental representations of significant people. This involves tracking him or her over a longer period, which typically requires the ability to perceptually recognise the person, but need not. For instance, I might not recognise a sibling, waiting for me at the airport, after a full makeover, but I continue to track her in my memory. These are the people I tend to direct behaviour toward, the people whose feelings I care most about. But I also direct actions with ethical consequences, or have the power to do so, toward people I don't know, people in my country and outside of it. I need to represent these people adequately in order to make ethical decisions about them.

Of course, the requisite level of detail in my mental representations of other people differs in accord with the specificity of my moral relations to those people. A number of broad ethical obligations can be derived simply by acknowledging that another person is a person-one doesn't need to know much about a person to conclude that she has certain basic rights, or that she would rather not suffer. Other, somewhat narrower obligations derive from the juxtaposition of social roles: understanding and meeting my basic obligations to my students does not, in general, require that I know very much about each student individually, although surely it depends on my ability to remember which ones are my students. And more specific zones of moral concern and action, 
composing a huge portion of our interpersonal lives, would be impossible to navigate without the ability to form and manipulate detailed representations of other people. A doctor's obligations may depend on knowing about a particular patient's medical history or tolerance for pain. A host's obligations may depend on knowing what some guests will happily eat and what others, for religious or medical reasons, cannot. And our relationships with those closest to us-friends, spouses, family-depend crucially on knowing what these unique persons think, need, fear, desire, and care about. To treat these relationships with no more particularity than we do our obligations to strangers would be not just odd but morally dysfunctional.

Executive functions operate on the information detailed above to instantiate the following capacities crucial to legal and moral agency:

Planning. The brain employs different types of planning processes, depending on the content of the planned actions and the time scale involved. Planning has clear ethical implications. Planning does not occur de novo. Most actions we plan are tokens of a type of action we have performed many times. We plan how to ask someone for something, how to express displeasure to someone, how to accomplish important tasks, and how to convey bad (or good) news to someone. Adults have had time to establish habits of planning. If the person has established ethical habits-for instance, the tendency to attach a high weight to the interests of others-certain types of selfish actions will be ruled out because they have not been established as habits.

Mindreading. We need both perceptual processes, such as the mirror neuron system, and cognitive processes, such as the ability to represent the mental states of another person, in order to use those representations in the planning of behaviour involving that person. This is vital to taking another person's needs into consideration when we act. A set of cortical areas known as the default mode network can become active during what appears to be a type of mindreading. ${ }^{40}$

Emotional regulation. We need to be able to express our emotions in certain ways and at certain times and places. Sometimes we have to inhibit them, to keep from crying, to hold in our anger. Children are notoriously bad at this, and adults can exhibit a range of emotional control. Disinhibition of emotional behaviour can also happen later in life as a result of a stroke.

Inhibition. There are multiples types of inhibition, supported by multiple brain processes and their constituent areas. The sort of inhibition required to state the colours of the words in the Stroop Test, rather than to read the words 
themselves out loud, is not the same process as the inhibition that keeps us from proposing a certain strategy at a board meeting when we recall that the board had failed earlier at a similar strategy ${ }^{41}$ When actions are ongoing, we monitor them with executive processes so that, when a mistake or something unintended occurs, we can inhibit the action and either quickly try another routine action, or step back and think about it a bit, i.e. engage other executive processes involved in planning more complex actions.

Some people, fortunately, tend not to form malevolent desires in the first place, and one might think that such people would need fewer inhibitory resources. We suspect that even these people need inhibitions, however. For example, to be alive and human is to experience immense attraction to someone who is rendered off limits to you by way of some social or ethical convention you accept: the spouse of a close friend, a boss, someone much older or younger than you. Something needs to stop this attraction from getting too far, or at the very least, from initiating actions. To put the point more generally, moral deliberation is only one type-albeit an extremely important type-of practical reasoning, and executive functions apply to all types of practical reasoning. Stopping oneself from overeating may or may not be an ethical matter, but we accept that there might be a person who was both morally excellent and extremely poor at inhibiting the desire to overeat, or overconsume anything, so that this ethically good person still lacked another type of inhibition.

Apparently one executive fault that psychopaths have is the inability to correct for an insufficiently large feeling of empathy. ${ }^{42}$ In planning actions involving other people, they need to be aware of their deficit and adjust accordingly (assuming that they want to fit into the society as members of it rather than predators upon it). This is not as hard as it sounds. The majority of memory patients, for instance, are quite aware of their bad memories, and will warn anyone they report one to. They are happy to admit when they don't remember something. This ability to admit ignorance, and to warn the unsuspecting listener of the low quality of their reported memories can only be accomplished with the aid of high level, prefrontal executive processes associated with memory. ${ }^{43}$ The minority of memory patients who are not aware of their deficit typically have prefrontal damage affecting executive function. These are the

41 See, e.g., Antonio Damasio, Descartes' Error (G.P. Putnam and Sons, New York, 1994).

42 Robert Blair and Lisa Cipolotti, 'Impaired Social Response Reversal', 123 Brain (2000) 1122-1141.

43 See William Hirstein, Brain Fiction: Self-Deception and the Riddle of Confabulation (MIT Press, Cambridge, MA, 2005). 
ones who tend to produce memory confabulations, because they are unable to monitor and check their false memory reports. We can all produce false memories on occasion, but we are able to keep the percentage low by correcting ourselves, usually by using other knowledge sources, such as our own memories, ${ }^{44}$ or external sources, such as the internet.

In urging the establishment of an acceptable minimum age of criminal responsibility, the Beijing Rules' Commentary quoted supra claims that culpability rests on whether a person possesses the 'discernment and understanding' expected of an adult. ${ }^{45}$ That phrase, we submit, should be cashed out in terms of adult-level executive functions - those interlinked capacities for guiding and regulating behaviour, which are grounded in, though not exhausted by, the PFC. The general sense that juveniles are unfit, or less fit, for blame and punishment is an accurate one, because the brains of children and adolescents are still works in progress-particularly with respect to the maturity of executive functions. Being culpable requires a mature, normally functioning set of executive processes; child soldiers, simply in virtue of being children, will often fall short of that condition. To see why, we must grasp how executive functions develop prior to adulthood, and how those processes of development can be systematically damaged by exposure to stress, trauma, and violence.

\section{$3 \quad$ Moral Development in the Juvenile Brain}

Converging evidence from behavioural studies and neuroscientific work shows that executive functions, and the brain structures that underwrite them, continue maturing through early adulthood, with the 'perfect storm' of high impulsivity, emotional volatility, and reward-seeking behaviour occurring during mid-adolescence - the very period in which child soldiers are most likely to be recruited. ${ }^{46}$

44 Marcia K. Johnson, Scott M. Hayes, Mark D’Esposito, and Carol L. Raye, 'Confabulation', in J. Grafman and F. Boller (eds.), Handbook of Neuropsychology (Elsevier, New York, 200o), pp. $383-407$.

45 Office of the United Nations High Commissioner for Human Rights, supra note 19.

46 Truly comprehensive numbers are for obvious reasons elusive, but for converging data, see Anke Köbach, Susanne Schaal and Thomas Elbert, 'Combat High or Traumatic Stress: Violent Offending Is Associated with Appetitive Aggression but Not with Symptoms of Traumatic Stress', 5 Frontiers in Psychology (2015) 1-10; Roland Weierstall, Roos Haer, Lilli Banholzer and Thomas Elbert, 'Becoming Cruel: Appetitive Aggression Released by Detrimental Socialisation in Former Congolese Soldiers', 37 International Journal of Behavioral Development (2013) 505-513; Anselm Crombach and Thomas Elbert, 


\subsection{The Neurodevelopment of Executive Function}

Since Aristotle, and surely before, human beings have recognised that young people, especially those caught in the adolescent maelstrom of immaturity and emotional turmoil, are distinctively prone to rash, risky, and sometimes ruinous behaviour. ${ }^{47}$ The tools of contemporary neuroscience and psychology, by probing executive abilities and their corresponding networks in the brain, have finally started to reveal the mechanisms behind these phenomena. This section contains a brief review of developmental psychology and neuroscientific evidence of executive functions, beginning with the question of whether executive functions even constitute a unified phenomenon that is developmentally traceable.

In the early years of the field, two theoretical views dominated: one conceiving of executive function as an essentially unitary construct with several constituent parts, the other framing executive function as comprising a set of dissociable processes-including attention, task-shifting, working memory, planning, and inhibition — with distinct developmental paths. ${ }^{48}$ In the last fifteen years, integrative models that stress 'unity and diversity' have come to prominence, if not dominance. ${ }^{49}$ The unity-and-diversity view construes executive functions as undergirded by a mechanism that develops throughout childhood and adolescence, even into adulthood, yet consisting of distinct components, many of which have been shown to be doubly dissociable (i.e., each one can be damaged without affecting the operation of the other).$^{50}$

'Controlling Offensive Behavior Using Narrative Exposure Therapy a Randomized Controlled Trial of Former Street Children', 3 Clinical Psychological Science (2015) 270-282; Bernd Beber and Christopher Blattman, 'The Logic of Child Soldiering and Coercion', 67 International Organization (2013) 65-104; Cecilia Wainryb, “And So They Ordered Me to Kill a Person": Conceptualizing the Impacts of Child Soldiering on the Development of Moral Agency', 54 Human Development (2011) 273-300.

47 Aristotle (trans. George Kennedy), On Rhetoric (Oxford University Press, New York, 2007), Book II, Chapter 12.

48 Nancy Garon, Susan E. Bryson and Isabel M. Smith, 'Executive Function in Preschoolers: A Review Using an Integrative Framework', 134 Psychological Bulletin (2008) 31-60.

49 An idea first proposed in Hans L. Teuber, 'Unity and Diversity of Frontal Lobe Functions', 32 Acta Neurobiologiae Experimentalis (1972) 615-656; for the classic contemporary articulation, see Akira Miyake, Naomi P. Friedman, Michael J. Emerson, Alexander H. Witzki, Amy Howerter, and Tor D. Wager, 'The Unity and Diversity of Executive Functions and Their Contributions to Complex "Frontal Lobe" Tasks: A Latent Variable Analysis', 41 Cognitive Psychology (2000) 49-100.

5o John R. Best, Patricia H. Miller, and Lara L. Jones, 'Executive Functions after Age 5 : Changes and Correlates', 29 Developmental Review (2009) 180-200, p. 183; see also Sarah-Jayne Blakemore and Suparna Choudhury, 'Development of the Adolescent Brain: Implications 
Although the fine details of this picture are still being filled in, the upshot is unmistakable: even an older adolescent is likely to possess a set of executive functions that is still short of complete maturity. True, some executive functions-working memory, for one-appear to reach maturity during adolescence; but many others, such as the ability to delay gratification or plan future actions, continue to change well into early adulthood. ${ }^{11}$ The prefrontal cortex (PFC) remains the locus of most executive activity, and in terms of structural integrity, connectivity, and function, adolescents lack a fully mature PFC. ${ }^{52}$ Of particular concern is a lack of development in how the executive functions interact with the brain's emotional systems; indeed, researchers increasingly agree that adolescents are distinctive in the sensitivity of their executive functions to emotional and incentive contexts. ${ }^{53}$ The relative immaturity and fluidity of frontal structures in the juvenile brain is compounded by comparable levels of immaturity and change in subcortical structures, such as the amygdala and striatum, as well as in the cortico-subcortical connections that mediate communication between executive networks and systems that govern socioemotional experience and reactivity. ${ }^{54}$

To appreciate the difficult hand young people are dealt, first consider that strong emotions and short-term desires can occasionally overwhelm even a mature, self-controlled adult. Now, consider that young people-and particularly adolescents — must navigate the stormiest of affective weather without a fully-developed set of executive control equipment. As a result, at times it may be virtually impossible for adolescents to reason counterfactually or anticipate

for Executive Function and Social Cognition', 47 Journal of Child Psychology and Psychiatry (2006) 296-312; Garon et al., supra note 48; Beatriz Luna, Aarthi Padmanabhan, and Kirsten O'Hearn, 'What Has fmRI Told Us About the Development of Cognitive Control through Adolescence?', 72 Brain and Cognition (2010) 101-113; Monica Luciana, 'Adolescent Brain Development in Normality and Psychopathology', 25 Development and Psychopathology (2013) $1325^{-1345}$.

51 Tomáš Paus, 'Mapping Brain Maturation and Cognitive Development During Adolescence', 9 Trends in Cognitive Sciences (2005) 6o-68; Laurence Steinberg, Dustin Albert, Elizabeth Cauffman, Marie Banich, Sandra Graham, and Jennifer Woolard, 'Age Differences in Sensation Seeking and Impulsivity as Indexed by Behavior and Self-Report: Evidence for a Dual Systems Model', 44 Developmental Psychology (2008) 1764-1778.

$5^{2} \quad$ Luciana, supra note 50.

53 Anastasia Christakou, 'Present Simple and Continuous: Emergence of Self-Regulation and Contextual Sophistication in Adolescent Decision-Making', 65 Neuropsychologia (2014) 302-312, p. 304.

Ibid. 
the potential consequences of their actions. ${ }^{55}$ Young people find themselves encountering intense and urgent impulses, but lacking the tools to curtail or control them; imagine someone turning on a firehose before you've managed to get both of your hands on it. The strong adolescent disposition to seek rewards and sate appetites is not balanced out by the kind of developed selfregulatory capacity capable of reining in such impulses, and this swirl of neural immaturity produces a pronounced inclination toward risky or dangerous behaviour. ${ }^{56}$

\subsection{Child Soldiers: Not Yet Full Moral Agents}

Because children's executive functions are still under development, they are less effective planners, inhibiters, and controllers of their emotional states. This means that several capacities crucial to legal and moral agency are not fully realised, and children can be located on a continuum of diminished moral agency. In addition, children also possess less-established moral characters. One need not embrace virtue theory to accept the claim, widely recognised if not uncontroversial, that a full picture of moral agency must include character traits, broadly understood as stable dispositions to act in certain ways in some relevant set of circumstances. ${ }^{57}$ Such dispositions become stabilised by practicing the relevant behaviours over an extended period of time, similar to the process of developing any brand of expertise. A stable disposition toward, for instance, honesty, is built up as a result of making appropriately honest choices in response to the right sort of environmental circumstances. Similarly, the trait of cruelty can become entrenched as the result of choices to be cruel to others.

For these traits-or their bearers-to be the proper object of praise, blame, or punishment, they cannot be developed 'mindlessly'; consideration and execution of a courageous action in a given set of circumstances requires executive guidance. This allows errors to be corrected, and it also keeps the practice active - open to continued modification given complex environments. Hence, from our perspective this process of habituation of dispositions is directed by

55 Abigail A. Baird and Jonathan A. Fugelsang, 'The Emergence of Consequential Thought: Evidence from Neuroscience', 359 Phil. Trans. R. Soc. Lond. B (2004) 1797-1804, p. 1802.

56 Laurence Steinberg, 'A Dual Systems Model of Adolescent Risk-Taking', 52 Developmental Psychobiology (2010) 216-224, p. 222.

57 See, for instance, Julia Driver, Uneasy Virtue (Cambridge University Press, Cambridge, 2001); Julia Annas, 'The Structure of Virtue', in Linda Zagzebski and Michael DePaul (eds.), Intellectual Virtue: Perspectives from Ethics and Epistemology (Oxford University Press, New York, 2003), pp. 15-33; Jonathan Webber, 'Virtue, Character and Situation', 3 Journal of Moral Philosophy (2006) 193-213. 
executive functions, and the process becomes more complex as persons get older and develop a more sophisticated executive suite of capacities. Planning, memory, attention, and inhibition are all ways in which practical reason both makes choices for action (given a particular goal) and establishes future dispositions to act.

As persons age, they develop the capacity to deliberately intervene on their future selves by manipulating their dispositions and environment, and thus the way in which they will act in a given circumstance. ${ }^{58}$ Because adults have this sort of diachronic control over their dispositions and actions, we are in a 'very real sense responsible for who we are' and any harm we might cause to others. ${ }^{59}$ Adina Roskies provides examples of the diachronic self-interventions that ground normal adult agency, including the ability to engineer one's environment so that it elicits or makes manifest valued dispositions, and does not realise those disvalued; intervening on ones' future self by making commitments to future behaviour or setting overarching policies; and practicing and strengthening the processes of self-control (agents can practice making decisions in a way that increases deliberative control). ${ }^{60}$ The executive processes are what intervene to stop routine behaviour, and these interventions can have a unified purpose, in this case the formation of one's self over time.

This capacity for habituation of traits and diachronic self-control is relevant to the evolving capacity of juvenile culpability, especially the culpability of child soldiers. In general, the prefrontal executive functions that allow the process of self-directed top-down control of the habituation of traits are still under development well into the late teenage years and early twenties. In young children, parents or other adults tend to direct the process of habituation of certain traits, pairing positive or negative emotions with particular outcomes and reflecting upon the consequences of particular courses of action. Dispositions to act are still very much under construction in teens, with fewer dispositions established such that they could be considered 'stable' and not subject to being undermined by outside factors such as peer pressure. Adolescents begin to exhibit independence with regard to habituation of traits and character, but their dispositions have yet to become stable, and they have heightened emotional states, which can derail reflection on the best choice given a desired trait (e.g., courage) or outcome, as well as undermine the pairing

58 Adina L. Roskies, 'Don't Panic: Self-Authorship without Obscure Metaphysics', 26 Philosophical Perspectives (2012) 323-342.

59 Ibid., p. 331.

6o Ibid. 
of positive emotional reinforcement and good outcomes. Juveniles are thus moral agents still in-the-making, which is one reason why they are universally subject to diminished culpability under the law.

Because juveniles are just beginning to self-direct the process of habituation, and have few stable dispositions, they are especially vulnerable to manipulation of the habituation process. As mentioned above, both juvenile peers and adults can impact an adolescent's adoption of character traits and process of moral development. To take one example of how 'internal' neural immaturity is linked with a heightened susceptibility to 'external' forces of control and influence, a study of ten-year-olds found that the degree of functional connectivity between three different neural systems-including $\mathrm{PFC}$ - correlated with resistance to peer influence. ${ }^{61}$ Such findings confirm our intuitive sense that the less able one is to rationally control and direct one's own thoughts and actions, the more one will be open to influence, coercion, and exploitation by others.

This perspective on juvenile culpability also explains why young people are so much more susceptible than adults to coercion, manipulation, indoctrination, and social pressure from peers and adults - all of which are typical and salient features of child soldiering. ${ }^{2}$ Children and adolescents are not simply 'weaker' versions of adult moral agents, possessing fully-formed characters but an underdeveloped ability to express those characters in action; their executive immaturity puts them at risk of having their agency hijacked altogether, and this is precisely what happens to many child soldiers, who are often subject to extreme, violent manipulation not only of their actions and emotions, but their dispositions and values as well. This would seem to make possible a special sort of coercion, where not just a particular act, but an actor's character is compromised due to outside pressure, similar to cases of Stockholm syndrome or brainwashing.

Thus child soldiers suffer from multiple sources of diminished moral agency: the typical underdeveloped agency due to the fledgling nature of their reasoning processes and character traits, and the often violent and deceptive manipulation of such processes and traits by those who conscript and train them to be violent by nature. The culpability of child soldiers would, in turn, seem to be doubly reduced.

61 Marie-Helène Grosbras, Marije Jansen, Gabriel Leonard, Anthony Mcintosh, Katja Osswald, Catherine Poulsen, Laurence Steinberg, Roberto Toro, and Tomaš Paus, 'Neural Mechanisms of Resistance to Peer Influence in Early Adolescence', 27 The Journal of Neuroscience (2007) 8040-8045.

62 Beber and Blattman, supra note 46, p. 68. 
What we have said so far should be sufficient to motivate the claim that many child soldiers, simply on grounds of neurobiological immaturity, are unfit for criminal prosecution. We will now attempt to develop this plausible notion into a more detailed proposal for an international legal standard, intended to answer the CRC's call to establish a uniform minimum age of criminal responsibility, and to provide a scientifically-minded schema for handling the culpability of child soldiers.

An initial hurdle, as with any attempt to draw stark lines between categories of criminal offenders who will be treated as differently culpable, is the apparent arbitrariness of treatment of cases lying close to the drawn line. As we have already discussed, neurodevelopment occurs on a continuum, and different individuals develop at different rates. Even if one grants our claim that mature executive function is necessary for full criminal responsibility, it is implausible to think there is some particular age at which a child becomes, all at once, a normatively competent adult fit for full-fledged ascriptions of responsibility.

It is much more plausible to think in terms of an age range during which an adolescent's executive functions tend to achieve maturity. Laurence Steinberg, a leading authority on adolescent psychological development, estimates the bottom of this range to be around 15 years old, and the upper bound at around 22 years old, for normally developing individuals. ${ }^{63}$ There is an unavoidable tension between the gradual, continual nature of neurobiological maturation and the law's demand for tractable, well-defined legal categories. Yet, as David Brink points out, 'the law often draws lines in ways that generally, but nonetheless imperfectly, track the facts that matter. ${ }^{64}$ The realisation that such imperfections will be unavoidable should not stop us from trying as best we can, to 'achieve individualized justice, consistent with the use of a generally but imperfectly reliable boundary marker', ${ }^{65}$

How, then, should lines be drawn within this range, and what are the reasons that support any particular way of drawing them? If one assumes a roughly normal distribution of neurobiological maturity within the range described by Steinberg, then choosing the bottom of that range-the age of 15-would be overinclusive with respect to legal adulthood, because it would

63 Laurence Steinberg, 'Should the Science of Adolescent Brain Development Inform Public Policy?', 28 Issues in Science and Technology (2012) 67-78.

64 David O. Brink, 'Immaturity, Normative Competence, and Juvenile Transfer: How (Not) to Punish Minors for Major Crimes', 82 Tex. L. Rev. (2004) 1555-1989, p. 1578.

65 Ibid. 
classify many neurobiologically immature person as adults, treating them as fully culpable when, as we and others have argued, they are not. Choosing the top of this range - the age of 22 -would be a mistake for the opposite reason: it would be underinclusive, excluding many neurobiologically mature persons from criminal prosecution by classifying them as children. One might instead choose the midpoint of this range-around age 18-in the hope of minimizing and achieving equilibrium between the errors of under- and overinclusion; as Steinberg points out, 18 is already considered the age of majority in a large and diverse group of countries. ${ }^{66}$

Even this last approach might seem undesirably dichotomous, however, if the goal is to balance the value of a uniform legal standard with the demands of individualized justice. We think finer distinctions can justifiably be drawn without sliding into a purely case-by-case approach. To sketch a comparative illustration, consider how child labour laws work in the United States: below a certain adolescent age, children are not permitted to work. That age is the lower bound of a range within which juveniles are permitted to work, but are restricted with respect to the kind of work they can do, how many hours per week they can work, and so forth; these restrictions are lifted when the juvenile reaches the upper bound of that age range, and is thereafter classified as an adult (in this legal domain). ${ }^{67}$ This is, broadly, the sort of approach we favour.

A sound legal standard of child culpability should reflect new evidence of the extent to which executive functions continue to develop throughout adolescence and beyond. The minimal age of criminal responsibility should be complex enough to accurately reflect the developmental science, but simple enough to ground legal categories. We attempt to strike this balance using multiple stages of culpability and both rebuttable and irrebuttable presumptions. ${ }^{68}$ Specifically, we recommend that any child soldier under 15 should be afforded an irrebuttable presumption of incapacity. At such young ages - with age going proxy for the developmental maturity of executive function-it is simply not plausible to assign adult-level culpability to a child soldier, even one who may have been involved in brutal atrocities.

\footnotetext{
66 Steinberg, supra note 63 , p. 76

67 Ibid.

68 Our recommended proposal has allies and influences including, e.g., Brink, supra note 64; Elizabeth S. Scott and Laurence D. Steinberg, Rethinking Juvenile Justice (Harvard University Press, Cambridge, MA, 2009); Claire McDiarmid, 'What Do They Know? Child Defendants and the Age of Criminal Responsibility: A National Perspective', in Arts and Popovski, supra note 6, pp. 85-95.
} 
From ages 15 through 17 , there should be a strong, though in principle rebuttable, presumption of that same incapacity. If evidence could be produced, for instance, that a 17-year-old was possessed of adult-level executive functioning at the time of offense, this would tend to rebut his presumed incapacity, and count in favour of prosecuting him as an adult. ${ }^{69}$ The question of exactly what sorts of evidence would be admitted, and what the standards in this context should be, is one we cannot hope to address adequately here, but we may venture a few suggestions. Criminal courts are certainly not opposed in general to the admission of expert testimony or scientific evidence, and - as the above discussion illustrates-neuropsychology has developed increasingly effective experimental methods for probing executive function in adolescents. Some offenses are themselves suggestive of adult-level executive function; if an adolescent has committed a crime involving the formation and execution of a complex plan, that fact on its own might militate in favour of treating him or her as an adult for the purposes of criminal prosecution. ${ }^{70}$ However, if the adolescent were subject to intense pressure to follow another's plan, the court may be safe to presume incapacity.

What about child soldiers in their later teenage years who do not comfortably wear the label 'child', who appear to be willing or even enthusiastic combatants, and who may have directly committed exceptionally heinous acts? Again, assuming that defences of superior command, duress, or intoxication are not available, we contend that child soldiers in such cases may still qualify for exculpation, or at least reduced culpability, on grounds of incapacity with respect to executive function. We recommend a presumption of adult-level criminal capacity begin at age 18 -widely marked in international and humanitarian law as the endpoint of childhood-but even this presumption may be rebutted. Child soldiers, to state the obvious, are different from most juveniles, or even most juvenile offenders. Beyond their sheer neurobiological immaturity and vulnerability to manipulative habituation, child soldiers collectively present a nearly unique constellation of factors, each of which tends to reduce the sense in which they are operating with normal executive functions.

One might think of the following conditions as composing a sort of checklistnot meant to be exhaustive - that could be consulted in cases where the question of a child soldier's culpability cannot be more definitively settled. The more of these conditions that apply to a hypothetical child soldier-even one

69 McDiarmid, supra note 68.

70 For a brief but cogent discussion of these evidentiary issues, see Michael S. Pardo and Dennis Patterson, Minds, Brains, and Law: The Conceptual Foundations of Law and Neuroscience (Oxford University Press, Oxford, 2013). 
aged 18 or older - the more reason we have to think him or her incapable of bearing culpability.

\subsection{Proximity to Violence}

Child soldiers are virtually guaranteed to have been exposed-simply in the sense of having played witness - to intense and repeated violence. This is often true of adults in war-torn regions too, of course, but juveniles naturally tend to have less education, social status, political influence, physical strength, and financial wherewithal than do adults - and are therefore often powerless to resist, protest, or escape this exposure. Moreover, children and adolescents are especially vulnerable to the neuropsychologically disruptive effects of adverse experiences in general. ${ }^{71} \mathrm{An}$ overarching theme emerging from research in this area is that 'moving parts get broken': because young brains undergo such tremendous change, particularly with respect to the neural structures subserving executive function, the damage when these developmental processes are disrupted can be especially severe. ${ }^{72}$ Children and teenagers are at higher risk of cognitive, affective, and addictive disorders - and are more likely to experience severe and debilitating forms of such disorders. ${ }^{73}$

Beyond the general fact that growing brains are susceptible to being profoundly reshaped through experience-for good or ill—early-life exposure to stress and violence is particularly harmful to the maturation of PFC and related systems. ${ }^{74}$ PFC is "exquisitely sensitive" to the effects of early exposure to

71 Alisa Powers and B.J. Casey, 'The Adolescent Brain and the Emergence and Peak of Psychopathology', 14 Journal of Infant, Child, and Adolescent Psychotherapy (2015) 3-15; Leah H. Somerville, Rebecca M. Jones, and B.J. Casey, 'A Time of Change: Behavioral and Neural Correlates of Adolescent Sensitivity to Appetitive and Aversive Environmental Cues', 72 Brain and Cognition (2010) 124-133; Luciana, supra note 50.

72 Tomáš Paus, Matcheri Keshavan, and Jay N. Giedd, 'Why Do Many Psychiatric Disorders Emerge During Adolescence?', 9 Nature Reviews Neuroscience (2008) 947-957, p. 954. See also Powers and Casey, supra note 71.

73 Ibid.

74 Amy Arnsten, 'Stress Signalling Pathways That Impair Prefrontal Cortex Structure and Function', 10 Nature Reviews Neuroscience (2009) 410-422; Jamie L Hanson, Moo K. Chung, Brian B. Avants, Elizabeth A. Shirtcliff, James C. Gee, Richard J. Davidson, and Seth D. Pollak, 'Early Stress Is Associated with Alterations in the Orbitofrontal Cortex: A TensorBased Morphometry Investigation of Brain Structure and Behavioral Risk', 30 The Journal of Neuroscience (2010) 7466-7472; Hilary K. Mead, Theodore P. Beauchaine and Katherine E. Shannon, 'Neurobiological Adaptations to Violence across Development', 22 Development and Psychopathology (2010) 1-22; Seth D. Pollak, 'Mechanisms Linking Early Experience and the Emergence of Emotions: Illustrations from the Study of Maltreated Children', 17 Current Directions in Psychological Science (2008) 370-375. 
violence, which can produce deficits in executive function and emotional regulation, which are in turn linked to a host of psychopathologies, including aggressive behaviour, PTSD, depression, and anxiety. ${ }^{75}$ And when the violence is "proximal, intense, and chronic," as it so frequently is for child soldiers, these risks and ill effects are even more pronounced. ${ }^{76}$

\subsection{Forcible Recruitment and Coercive Treatment}

Child soldiers are seldom mere witnesses to violence, sadly; they are often made victims of coercive violence as well. Compared to their adult counterparts, child soldiers are far more likely to have been initially forced into military service. The reasons are complex but hardly counterintuitive, and the most straightforward explanation is simply put: compared to an adult, a juvenile is more easily (and cheaply) manipulated by force and the threat of force. ${ }^{77}$ They are less likely to rebel, or to temporarily feign cooperation, than adults are. They are less likely to attempt escape-partly because a kidnapped child, taken away from his or her home, is more likely to be spatially and geographically disoriented, which makes escape seem a particularly hopeless option. ${ }^{78}$ For broadly similar reasons, child soldiers are more frequently 'managed' by coercive treatment and harsh punishment than are their adult counterparts. ${ }^{79}$ And as discussed above, the growing brain is particularly susceptible to the pathologies that can result from being the repeated targets of violence and abuse. ${ }^{80}$ So although adult soldiers may also be targeted for coercive, violent treatment, their younger counterparts are more likely to be so targeted, and more vulnerable to the psychologically distorting effects of violence and coercion.

\subsection{Appetitive Aggression}

The link between aggressive behaviour and pathologies distinguished by negative emotions, such as anger and fear, is already well understood; in recent years, however, researchers have begun to reveal the disturbing extent to which positive emotions - feelings of pleasure, power, and control—can become pathologically linked to the commission of violence. Those studying this

\footnotetext{
75 Mead et al., supra note 74, pp. 15-17.

76 Cecilia Wainryb and Monisha Pasupathi, 'Political Violence and Disruptions in the Development of Moral Agency', 4 Child Development Perspectives (2010) 48-54, p. 48.

77 Beber and Blattman, supra note 46.

78 Ibid.

79 Ibid.

8o $\quad$ Mead et al., supra note 74 .
} 
phenomenon use the term appetitive aggression to describe violence that neither functions as a means to an end nor as a reactive response to fear, but as something intrinsically enjoyable. ${ }^{81}$

Significantly, the link between PTSD and exposure to violence seems to cut across perpetrators of, witnesses to, and victims of violence more or less equally-but the most significant predictor of appetitive aggression is the amount of violence one has perpetrated. ${ }^{82}$ Even more important for the present discussion, this effect is especially salient in the young, as the age of entry into an armed group appears to factor crucially into the development of appetitive aggression. ${ }^{83}$ It is easy to see why: when a young person joins an armed group, 'the process of civil socialization that is essential for the regulation of appetitive aggression is impaired and replaced by the socialization in an armed movement that fosters violent and aggressive behaviour. ${ }^{84}$ Appetitive aggression may even serve as a sort of adaptation or defence mechanism, "inoculating" against the most severe symptoms of PTSD. ${ }^{85}$ The picture emerging from this research, much of which is done with children and adolescents, is that of an awful feedback loop: appetitive aggression rises as one commits more and more acts of violence, reinforcing the fascination held by violence and making further atrocities even more likely.

Appetitive aggression merits extra attention here because of the deceptive role it might play —if not properly appreciated —in determining the culpability of a child soldier. Imagine a young man who, as part of an armed rebel group, committed violent atrocities during his teenage years. His exact age is unknown: he is not young enough to be obviously beyond the proper reach of prosecution, but neither is he old enough to be uncontroversially tried as an adult. Now suppose that he, from within this legal grey area, testifies that he actually enjoyed some of his violent acts, and that even after leaving the rebel

\footnotetext{
81 Crombach and Elbert, supra note 46 .

$82 \quad$ Ibid.

83 Weierstall et al., supra note 46, p. 506. For the original finding, see Tobias Hecker, Katharin Hermenau, Anna Maedl, Thomas Elbert, and Maggie Schauer, 'Appetitive Aggression in Former Combatants-Derived from the Ongoing Conflict in DR Congo', 35 International Journal of Law and Psychiatry (2012) 244-249.

84 Weierstall et al., supra note 46, pp. 506-7.

85 Tobias Hecker, Katharin Hermenau, Anna Maedl, Maggie Schauer, and Thomas Elbert, 'Aggression Inoculates against PTSD Symptom Severity-Insights from Armed Groups in the Eastern DR Congo', 4 European Journal of Psychotraumatology (2013); Roland Weierstall, Susanne Schaal, Inga Schalinski, Jean-Pierre Dusingizemungu, and Thomas Elbert, 'The Thrill of Being Violent as an Antidote to Posttraumatic Stress Disorder in Rwandese Genocide Perpetrators', 2 European Journal of Psychotraumatology (2011).
} 
group he has continued a pattern of violent behaviour. Such testimony might seem to be evidence of cold cruelty, malice, or remorselessness, and might count against a presumption of incapacity.

But if appetitive aggression is a predictable pathological response to conditions forcibly initiated during childhood or adolescence, our hypothetical soldier's testimony might be more accurately seen as evidence of disordered executive functioning. Upon noticing that one has caused a defenceless person great pain, for instance, someone with well-functioning executive processes would be expected to recoil in empathetic identification, akin to the way one might reflexively duck upon watching someone walk into a low-hanging tree branch. But persons with pathological appetitive aggression react oppositely: they are excited and spurred on by the perception that they have hurt someone else. Compared to adults, child soldiers are especially likely to evince this disordered relationship between the causing of pain and the feeling of pleasure, and we should be open to counting this pathology among the possible contributors to exculpatory incapacity.

\subsection{Initiation and Indoctrination}

Armed groups employing child soldiers often force their new recruits to perform rites of initiation; indeed, even within these groups, children are more likely than adults to be subject to such rites. ${ }^{86}$ Recruits are sometimes made to commit acts that are both traumatic and identity-transforming, like the murder of a family member or the defilement of a neighbour's corpse. It is worth considering this phenomenon in light of the foregoing discussion about appetitive aggression: after all, if participating in violence is part of the price of admission to an armed group, recruits may be on a trajectory toward increased levels of appetitive aggression even before they begin participating in 'official' hostilities as part of the group. Furthermore, these initiation rites can serve to dissolve ties between recruits and their social habitats, which is a particularly dangerous outcome for young people. Even if adults and children were forced with equal frequency to perform similarly horrific rites of initiation-which they are not, the evidence indicates — an adult is more likely to have already established strong bonds within his or her community, which even a profound violation of that community's norms will be hard to break. By contrast, child soldiers who are forced to kill a family member or assist in torturing a prisoner may find themselves cut off from the communities that raised them, beyond the hope of reconciliation or return. The more complete and permanent the recruit's traumatic disconnection from his or her community, and the earlier 
that separation occurs, the more remote are the recruit's chances are for subsequently qualifying as a responsible agent. ${ }^{87}$

In combination with initiation rites, armed groups commonly use indoctrination to keep their younger recruits under control. This indoctrination can take the form of misleading political propaganda, selective suppression of information or access thereto-for instance, seizing all radios within the armed group once leaders learned that offers of amnesty were being broadcast—or spiritual or religious brainwashing. ${ }^{88}$ Such measures do not merely fill a recruit's head with false information or feelings of allegiance; they serve to bring the recruit's habits of thinking, acting, and making decisions in line with the priorities of the military leaders who command them. Again, indoctrination measures are not unique to child soldier populations, but child soldiers are significantly more likely to be subject to such measures than their adult counterparts - for the intuitive reason, borne out by the available data, that children are more susceptible to this kind of manipulation. From the strategic perspective of these leaders, the relative ease of indoctrinating children can offset their comparative ineffectiveness as fighters. Indoctrination is not a coincidental by-product of conflicts involving child combatants; it is rather a deliberately adopted tactic to produce allegiance, fear, and unquestioning obedience in their youngest recruits. ${ }^{89}$

\section{5}

\section{Conclusions}

When child soldiers are enlisted to participate in war crimes, the moral and legal questions raised are difficult to answer. We may have an overwhelming sense that the perpetrators of such crimes must be held to account. At the same time, we are likely to experience a strong intuition that children, particularly those whose childhoods have been poisoned by the horrors of war, and who may be under the direct and coercive influence of adult commanders, cannot be fit targets of blame. International law has thus far been unable to resolve this tension by providing a coherent uniform standard governing the culpability of child soldiers, or even a minimum age of criminal responsibility. When other defences are not available, what should be done? The problem demands an international legal standard that balances cross-cultural uniformity with flexibility and context-sensitivity, and which can be given a coherent and well-grounded rationale.

$\begin{array}{ll}87 & \text { Ibid. } \\ 88 & \text { Ibid. } \\ 89 & \text { Ibid. }\end{array}$


We believe our approach is a step in the right direction. Because the graded structure of culpability we recommend is rooted in broadly invariant facts about the development of executive functions in the human brain, it can be consistently and fairly applied across a wide range of contexts. At the same time, it makes room for the context-specific facts of particular cases and local norms, and marks the gradual but genuine maturation of executive functioning that occurs in late adolescence and early adulthood. In the most general terms, child soldiers should be presumed unfit for attributions of blame because (i) their executive processes are still significantly under construction; and (ii) those very tools of self-governance, already immature, are often subject to manipulative and violently coercive exploitation.

These conditions apply most profoundly to the youngest child soldiers, and so we recommend an irrebuttable presumption of incapacity for any child soldier under 15 . We leave open the possibility in principle of making 15-to-17-yearolds targets of prosecution, but only if the presumption of incapacity can be rebutted-a prospect we regard as improbable in all but the most extreme cases. At 18 and above, one can be more fairly presumed to have executive functions robust enough to underwrite responsibility, but that presumption too can be rebutted; for instance, if there is evidence that one's crimes were committed in the throes of a severe psychopathology engendered by a prolonged period of abuse. 